\title{
A LUTA PELO DIREITO À CIDADE POR MEIO DA STREET ART EM CURITIBA, PR
}

\author{
The struggle for the right to the city through street art in Curitiba, PR \\ Luiz Henrique R. P. A. de Oliveira * \\ *Mestre pelo PPG em Geografia - UFPR - luizhr.oliveira@gmail.com.
}

Recebido em 07/05/2018. Aceito para publicação em 25/06/2018.

Versão online publicada em 10/08/2018 (http://seer.ufrgs.br/paraonde)

\begin{abstract}
Resumo: A street art contemporânea tem sua origem na década de 1970, em Nova Iorque, intrinsecamente ligada à cultura hip hop, responsável pelo surgimento de tais expressões artísticas no Brasil. Com suas particularidades locais, atualmente ela pode ser entendida como um gênero artístico híbrido, destacando-se duas contradições inerentes a ela: a dualidade entre a pichação e o graffiti e o seu caráter político e territorial. Resultado da pesquisa de mestrado concluída em 2016, o trabalho se baseou nos seguintes procedimentos metodológicos: revisão bibliográfica, trabalhos de campo, registros fotográficos, análise de documentários e entrevistas. Por meio de uma análise crítica foram identificadas características que explicitam, em maior ou menor grau, a luta pelo direito à cidade. Compreende-se, então, que de forma dialética a street art pode se caracterizar como uma prática transformadora em direção à uma sociedade radicalmente diferente.
\end{abstract}

Palavras-chave: street art; direito à cidade; arte de rua.

\begin{abstract}
Contemporary street art has its origin in the 1970's in New York, intrinsically connected to the hip hop culture, which was also responsible for the emergence of such artistic expressions in Brazil. With its own local singularities, it can be understood nowadays as a hybrid artistic genre, with two main inherent contradictions: the duality between graffiti and pichação and its political and territorial nature. The present paper is the result of a master studies concluded in 2016, based on the following methods of investigation: bibliographic review, fieldworks, photographic recording, documentary analysis and interviews. Using a critical approach to the analysis, it was possible to identify characteristics that feature the struggle to the right to the city. Therefore it is understood that street art can be dialectally considered as a transformation practice towards a radically different society.
\end{abstract}

Key-words: street art; the right to the city; graffiti.

\section{Introdução}

0 presente trabalho ${ }^{1}$ é uma análise da arte de rua (ou street art) em sua vertente gráfica e a luta pelo direito à cidade, a partir da seguinte hipótese: a de que a street art figura como uma forma de luta pelo direito à cidade, como um esforço utópico de transformação da sociedade.

Através de levantamento bibliográfico e documental, discussão teórica; entrevistas, trabalhos de campo e registros e análise de expressões artísticas, foram levantadas diversas contradições que compõe o objeto de estudo, em uma tentativa de entendê-lo enquanto processo. Assim, investiga-se como a arte de rua se faz presente no contexto da produção do espaço urbano e na luta pelo direito à cidade, assim como suas contradições inerentes, notadamente a dualidade entre pichação e graffiti e seu papel enquanto arte territorial e política. Por fim, compreender como esta forma de expressão

1 A dissertação pode ser acessada no portal do sistema de bibliotecas da UFPR e no link a seguir: <http://acervodigital.ufpr.br/handle/1884/47316>. 
artística figura como uma forma de luta pelo direito à cidade.

\section{Desenvolvimento}

\subsection{Da crise da cidade ao direito à cidade}

Para que se possa compreender a street art faz-se necessário o estudo da produção do espaço urbano na contemporaneidade. Harvey (1978) explica que, inserido em uma dinâmica capitalista, este processo não é apenas uma conseqüência, mas sim uma condição para a acumulação capitalista, o que pressupõe também a luta de classes.

Mais recentemente o autor destaca o papel da globalização e do neoliberalismo como potencializadores do desenvolvimento geográfico desigual e dos conflitos sociais (HARVEY, 2013).

Em consonância, Sposito (2011) afirma que não é possível pensar na cidade como uma unidade, uma vez que a lógica capitalista provocou a fragmentação do espaço, como consequência da reestruturação das redes urbanas que se tornaram extremamente complexas. Para a autora, em primeiro lugar, do ponto de vista da forma urbana e das condições que ela oferece, o tecido urbano se encontra fragmentado e a fluidez dentro dele é diferenciada de acordo com os segmentos sociais. Em seguida, ela aponta a diferença de apropriação do tempo e espaço urbano, uma vez que os interesses e escolhas são individuais, apesar de definidos historicamente. E, por fim, a existência de conflitos consequentes da relação entre a reprodução capitalista e a reprodução social, uma vez que há um afastamento entre o distante e o próximo, ou seja, conflitos de interesses econômicos e políticos, de agentes da produção do espaço urbano de escalas mais abrangentes e dos grupos sociais que habitam a cidade.

Lefebvre (2001) defende a existência de duas ordens que produzem a cidade (sendo esta uma mediação contida entre tais): a ordem próxima e a ordem distante. A primeira se trata das relações imediatas entre pessoas e grupos, da realidade prático-sensível, enquanto a segunda está instituída em um nível que impõe racionalidades, ideologias, culturas, tem um forte poder coator e torna-se visível na realidade, na imediatez.

Dessa forma, entende-se que a acumulação e a luta de classes produzem o espaço urbano de forma contraditória, porém essencial para o modo de produção capitalista. Como processo resultante disso, temos a cidade produzida por diferentes grupos que atuam de forma conflituosa e favorável a grupos poderosos. A fragmentação, a segregação e a exclusão resultantes desta dinâmica determinam diferentes formas de apropriação do espaço urbano, que variam de acordo com seus diversos grupos.

Lefebvre (2001) considera a cidade em si como uma obra, uma realidade complexa e contraditória, tendo necessariamente valor de uso, ou seja, de apropriação, de fruição, com um caráter orgânico de comunidade, de vida comunitária. Tal característica é oposta à produção capitalista da cidade, fundada na noção do valor de troca. Esta contradição evidencia o que o autor chama de "crise da cidade". É a partir desta ideia que Lefebvre introduz a noção de direito à cidade, que não constitui uma retomada à cidade antiga, mas uma renovação da cidade, como um direito à vida urbana:

0 direito à cidade se manifesta como direito superior aos direitos: direito à liberdade, à individualização na socialização, ao habitat e ao habitar. 0 direito à obra (à atividade participante) e o direito à apropriação (bem distinto do direito à propriedade) estão implicados no direito à cidade. (LEFEBVRE, 2001, p. 134, grifo no original).

Portanto, trata-se de uma perspectiva completamente revolucionária no sentido de transformação não apenas da cidade, mas do seu modo de produção, das relações sociais, do estilo de vida, enfim, da humanidade.

Assim, Lefebvre (2001) reforça que a mudança da vida urbana só pode ser feita a partir da mobilização social e da luta política, portanto este o direito não é abstrato, ele está ligado 
diretamente às nossas praticas diárias: "A implicação é que nós, individualmente e coletivamente, fazemos nossa cidade através de nossas ações diárias e de nossos engajamentos políticos, intelectuais e econômicos" (HARVEY, 2013, p. 31).

\section{2. $\quad$ A Street Art e suas contradições}

0 ato de escrever em paredes data da pré-história, mas o nome se origina do italiano graffito, plural de graffiare que significa "riscar", entretanto hoje o termo graffiti é utilizado indistintamente para plural ou singular (RAMOS, 2007). Entretanto o que hoje se conhece como graffiti (ou modern graffiti) tem sua origem em 1972 em Nova Iorque, diretamente ligado aos guetos e ao movimento hip hop, praticado em um primeiro momento por jovens negros e latino-americanos de baixa renda, normalmente com conteúdos ligados à afirmação de identidade do artista, como nomes ou pseudônimos, locais, etc. (RAMOS, 1994; PROSSER, 2009; CANCLINI, 2011). A partir daí o graffiti começou a se espalhar pelas metrópoles do mundo, na maioria das vezes como a vertente gráfica da cultura hip hop, juntamente com a poesia, a música e a dança.

Durante a pesquisa foram diversos os momentos em que foi possível perceber como a cultura hip hop é base para a prática do graffiti: além da bibliografia, como em Canclini (2011), Prosser (2009; 2010), Oliveira (2009), Ramos (1994; 2007), dentro outros, a cultura está presente em todos os materiais que envolvem o graffiti, seja nas explicações sobre o surgimento do movimento hip hop no Brasil, no documentário "Nos tempos da São Bento" (2010); no uso do rap como trilha sonora de alguns dos documentários analisados (NOS..., 2010; PIXO, 2009); nos diálogos com os entrevistados (GUSTAS, 2016; ANTI, 2016); no evento Street of Styles, que além da prática de graffiti, havia também disputa entre b-boys (dançarinos), música tocada por DJs e cantores e grupos de rap; além da infinidade de materiais publicados em plataformas online;

Dessa forma, é possível perceber como o graffiti também tomou força no Brasil a partir desta cultura, primeiramente na década de 1980, em São Paulo, especificamente na estação do metrô São Bento, berço do movimento hip hop brasileiro e ponto de encontro de pessoas do Brasil todo, onde as referências vindas de outras metrópoles do mundo eram partilhadas entre os frequentadores (NOS..., 2010). Além disso, ainda na década de 1970, já se encontravam graffiti e stencils ${ }^{2}$ (este representado na figura 1) do artista Alex Vallauri³ ${ }^{3}$ que trouxe várias influências principalmente da Europa com o stencil (PROSSER, 2010).

Ao se aprofundar nas discussões sobre a arte de rua, foi possível identificar contradições dentro do universo da street art, notadamente a dicotomia entre graffiti e pichação, que está presente na academia, na mídia, no universo dos artistas e na visão e ações do poder público. Esta dicotomia está pautada principalmente nas questões estéticas, de (i)legalidade e de (i)legitimidade das representações.

Silva-e-Silva (2008) considera que a pichação não pertence ao grupo das artes, pois é desprovido de estética e beleza, e também não pode ser considerado como comunicação, uma vez que não emite uma mensagem. Esta visão é compartilhada por grande parte da população e também pelo poder público, que, além de não entendê-la como arte, considera-a como vandalismo.

Já Nascimento (2015) apresenta uma visão oposta, de que a pixação tanto de São Paulo quanto do Rio de Janeiro quanto São Paulo apresentam similaridades estéticas, desde o projeto criativo até a técnica, como a característica da escrita, a execução em curto tempo e o raro uso de cores. No caso de São Paulo, a especificidade está no padrão estético, chamado, o Tag Reto, no qual a identidade visual vem dos cartazes e lambe-lambes de bandas de rock da década de 1980 da cidade, com inspiração nas runas nórdicas, mas derivando disto para um alfabeto e uma linguagem própria.

Nascimento (2015) diferencia a pichação em relação ao graffiti por: ter apenas uma cor; ser constituída de assinaturas e códigos que promovem diálogos entre grupos de pichadores, mas é

\footnotetext{
2 Stencil é uma técnica artística de pintura utilizando um molde como um negativo da imagem desejada, o que é chamado de "máscara". 3 O Dia Nacional do Graffiti é celebrado no dia 26 de março, em homenagem à data de falecimento de Vallauri, em 1987 (PROSSER, 2010 ).
} 
ilegível para a maioria dos leigos; ser considerada como crime ambiental pelo artigo 65 da Lei Federal 9.605/984.

Entretanto, quem transita pela cidade pode perceber que a lei não impede as pichações (MARINS, 2014). Nas entrevistas com os artistas as questões da ilegalidade da arte e da repressão por parte dos policiais apareceram nas falas. Isso também é marcante em todos os documentários, visto que a ilegalidade é inerente à prática da pichação.

Para Oliveira (2009), a principal rejeição da sociedade à pichação (com sua moral burguesa judaico-cristã, segundo ele), não está ligada à estética formal e moralizadora, da qual a maioria é educada, ou à autorização desta prática, mas sim ao seu caráter subversivo. Esta dimensão é bastante presente tanto no discurso dos artistas, quanto na literatura sobre o assunto e por vezes vai de encontro à prática do graffiti (ou graffiti art) que é legal, realizado normalmente de forma autorizada e considerado como mais aceito pela sociedade (OLIVEIRA, 2009).

Apesar de ser uma forma de expressão marginalizada e mal vista pela sociedade, entende-se que a pichação possui uma estética artística própria, e que sua importância vai muito além da técnica exigida, representando uma linguagem contemporânea propriamente urbana, que incorpora elementos de dimensões coletivas (como o diálogo entre os pichadores e a existências das crews grupos de pichadores), e também dimensões individuais (como a assinatura, o estilo de cada pichador e a apropriação territorial), e que pode promover o diálogo, mesmo que por vezes restrito aos artistas.

Entretanto, nas entrevistas e nos documentários fica claro que não apenas as pessoas que fazem graffiti começaram sua prática a partir da pichação, como continua sendo algo recorrente, o que desmistifica um pouco da visão de que o graffiti é ilegítimo no que tange a sua dimensão do protesto. Além disso, as expressões presentes nos muros são tão diversas que muitas vezes não se encaixam nas definições de graffiti e pichação, além de normalmente disputarem o mesmo espaço nos muros, criando uma composição complexa de representações.

Por todos estes aspectos, entende-se que tal distinção não contempla as diversas dimensões das representações e, tampouco, faz jus à diversidade que a própria arte promove, ou à grande variedade de artistas engajados em sua produção. Por isso a escolha dos termos street art (ou arte de rua) e graffiti para designar as mais diversas representações gráficas, reservando as particularidades para suas cinco vertentes: pichação, graffiti, sticker (adesivos), lambe lambe (pôsteres colados) e stencil, levantadas por Prosser (2009).

Atualmente, a arte de rua incorpora muitos elementos como a repetição da pop art, o estilo e a atitude do movimento hip hop, a massificação da propaganda e os avanços tecnológicos, por isso Viana (2009) diz que as representações artísticas na rua são produtos criativos do espaço urbano e incapazes de serem definidos em categorias artísticas estanques.

Para Canclini (2011) o graffiti (ou "grafite", na denominação do autor) é um gênero impuro, constitucionalmente híbrido, ou seja, são obras que se originam a partir da mistura de diferentes práticas espalhadas pelo mundo e que, quando aglutinadas, provocam a ressignificação de mundos, pessoas, tempos e espaços, de tal maneira que os paradigmas clássicos de arte não dão conta de explicar a pluralidade de suas referências.

0 autor entende também que o graffiti possui uma dimensão territorial de apropriação da cidade, ao mesmo tempo em que desconstrói a ideia de coleção patrimonial e dos bens materiais simbólicos. Além disso, exemplifica como os graffiti argentinos, em 1989, tinham relação com a situação política e econômica do país, misturando palavras e imagens, linguagem culta e popular e promovendo diálogos.

Canclini (2011) fala da desconstrução do sistema vertical de produção cultural, a partir do que ele

\footnotetext{
${ }^{4}$ No caso de Curitiba, a última lei que dispõe sobre a pichação foi aprovada em 2013 (Lei 14.367) alterando as leis anteriores (Lei no 8.984/1996, lei no 11.095/ 2004), aumentando o valor da multa para pichadores e comerciantes de tintas spray que não seguem a legislação.
} 
chama de culturas híbridas, ou seja, construções simbólicas que misturam elementos do culto, do popular e do massivo e que estão intimamente ligados com a vida nas cidades contemporâneas.

Segundo o autor, a hibridação, além de superar a divisão entre culto e popular, também deixa obsoleta a oposição política entre o que é hegemônico e o que é subalterno. Isto requer uma reflexão entrelaçada (ou oblíqua) sobre o poder e sua reorganização cultural. "Trata-se de analisar quais são as consequências políticas ao passar de uma concepção vertical e bipolar para outra descentralizada, multideterminada, das relações sociopolíticas". (CANCLINI, 2011, p. 345, grifos do autor), assim como dos fazeres artísticos, o que pode ser aplicado também par a dicotomia entre pichação e graffiti.

Isto, porque esta obliquidade tem outro papel, o de dar às relações culturais um importante lugar no desenvolvimento político, uma vez que a sociedade constrói representações simbólicas diante dos conflitos que surgem da ordem atual. A importância da atuação de práticas culturais não está simplesmente em atividades culturais organizadas, mas nos comportamentos ordinários, nas revoltas e descontentamentos diários, como é o caso da street art.

\section{A street art como luta pelo direito à cidade}

Com base na análise da literatura, dos trabalhos de campo, das entrevistas e também da experiência da vida urbana, foram selecionadas algumas características que ajudam a direcionar a reflexão sobre a street $\operatorname{art}^{5}$. Para elucidar a exposição, apresenta-se o raciocínio de uma forma enumerada, entretanto, é preciso ressaltar que estas características devem ser pensadas de forma dialética, considerando também as diversas contradições que envolvem estas formas de expressão artística.

a) trata-se de uma forma de expressão que se baseia na vida cotidiana e na vida urbana, ou seja, enquanto um produto da vida urbana, é criada, contestada, refeita, apropriada e ressignificada por pessoas que vivem a cidade diariamente;

b) são expressões que, em maior ou menor medida, evidenciam as desigualdades, protestam contra o sistema que está estabelecido, questiona a sociedade atual e suas imposições, seus símbolos e suas falácias;

c) é uma forma de arte que mostra que a cidade é construída para além da vontade do capital, mas também por cada um de seus habitantes, que pode imprimir suas angústias, vontades, paixões, brincadeiras, amores, ódios, conflitos e uma infinidade de outros sentimentos e impressões, que são próprios da vida do indivíduo e que revelam a "ordem próxima" (LEFEBVRE, 2001) da cidade;

d) trata-se também, de uma forma de apropriação (algumas vezes entendida como uma apropriação privada) da paisagem urbana, no sentido de que os artistas urbanos, assim como qualquer cidadão, se identificam ou se familiarizam com determinadas paisagens, e cruza a fronteira de ser um simples espectador, mas de alguém que contribuiu para a construção daquela paisagem visual;

e) Considerando que os suportes do graffiti são os muros, portas e ambientes abandonados e é fundado na contestação, no vandalismo, na subversão (apesar de todas as contradições relacionadas a isso), então se entende que ele contrasta com a propriedade privada, um dos principais elementos responsáveis pela exclusão social e espacial das cidades.

f) Como salienta Lefebvre (2001), a arte é em si um valor de uso, portanto carrega com ela o potencial de produção de uma cidade baseada no mesmo. Assim, a arte de rua cumpre esse papel, seja por meio de representações com a estética pouco aceita da pichação, seja com

\footnotetext{
5 Os registros fotográficos e as entrevistas foram partes fundamentais da análise e comprovação da hipótese no trabalho original, porém, devido ao formato deste artigo só foi possível apresentar algumas das imagens.
} 
aquela já mais assimilada, do graffiti art, mas que não deixa de ter seu poder de ressignificação e despertar de outras consciências, além de imprimir nas paisagens as inquietações dos indivíduos/artistas;

g) tendo em mente as contradições levantadas, os muros e as representações artísticas promovem um diálogo, uma forma, mesmo que conflituosa, de encontro, de convergência, de fluência e fruição do espaço urbano, característica fundamental e basilar da cidade.

Assim, entende-se que a street art por contestar direta ou indiretamente a propriedade privada e a organização da sociedade sob o sistema capitalista, ela se caracteriza como uma prática transformadora que, de forma dialética, pressiona a sociedade, o poder público e as estruturas sociais em direção ao questionamento, à reflexão e, por que não à criatividade de uma sociedade radicalmente diferente, realizando a "práxis emancipatória" da trialética (SOJA, 1996). Apesar da figura 1 conter diversos registros fotográficos feitos no centro de Curitiba que endereçam diretamente esta luta, fica claro que elas não são as únicas a ter este papel.
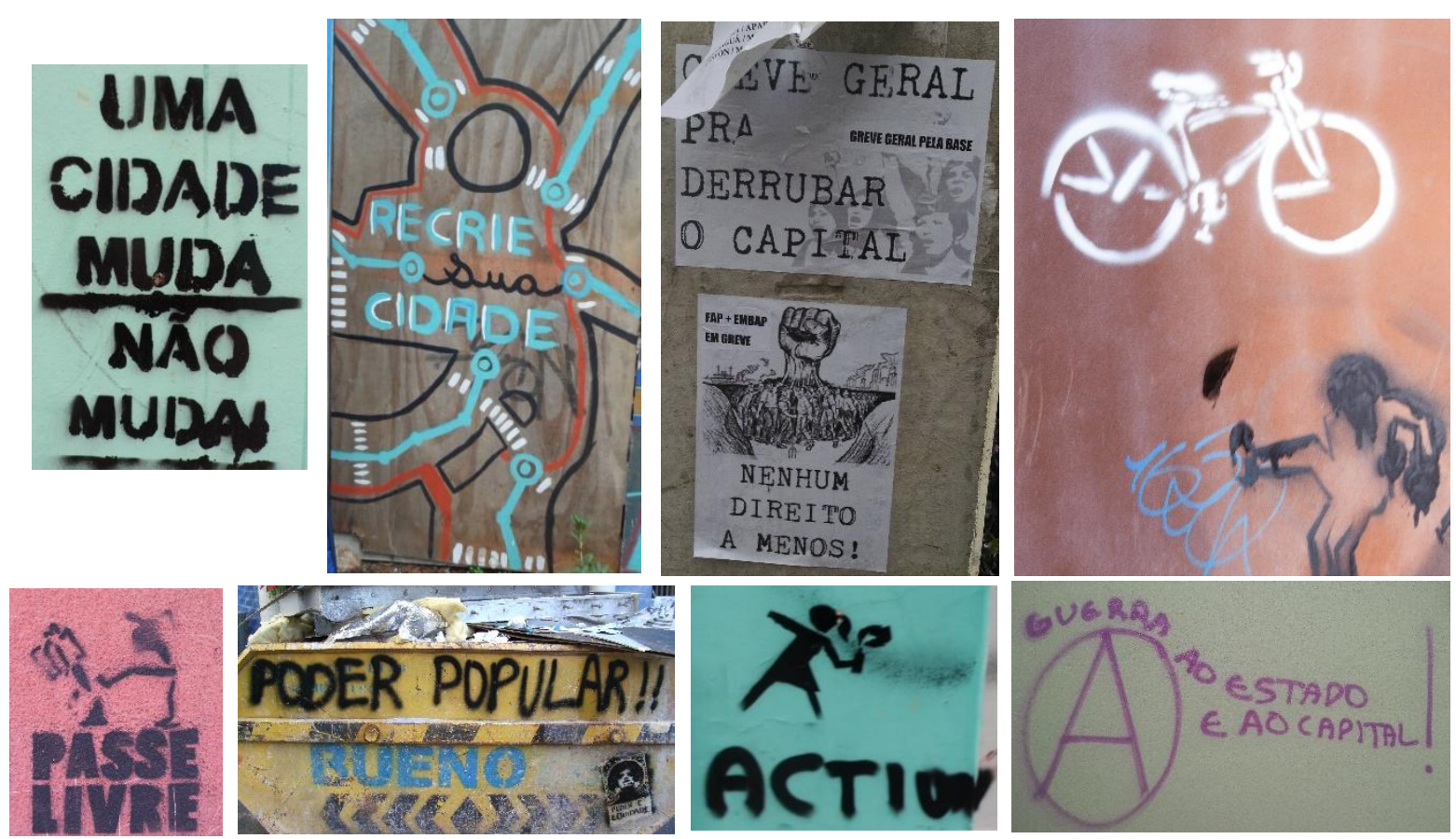

Figura 1 - Representações diversas no centro de Curitiba

Fotos: OLIVEIRA, L. H., 2011, 2014, 2015).

Outro entendimento possível, a partir da análise, é de que a street art pode ser compreendida como um fenômeno que transita, de forma dialética, entre três categorias da Geografia: o Espaço Urbano, o Território e a Paisagem, como ilustra a figura 2.

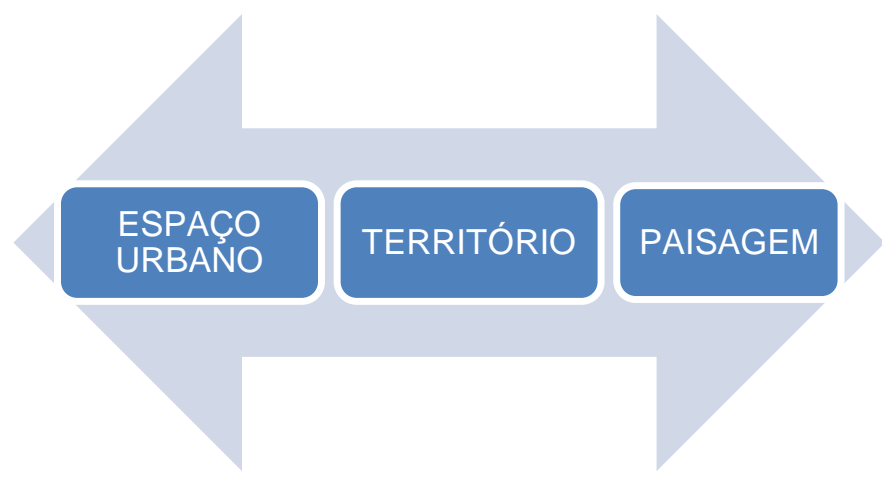

Figura 2 - Trânsito entre Espaço Urbano - Território - Paisagem 
A produção do espaço urbano, norteada por ideologias (do capital, do Estado, da religião, etc.), ao chegar ao nível local, contrasta com as formas de apropriação do espaço pelos diferentes grupos sociais, gerando conflitos. Estes conflitos entre as relações de poder se expressam, dentre outras maneiras, na forma de graffiti e pichações, alterando a dimensão sensível do espaço.

Entretanto, entende-se que a street art não é apenas um produto, mas um também um agente, com papel ativo na democratização da arte, na veiculação de informações, no fomento do diálogo, na fruição do espaço urbano e, por isso, é percebida como uma possibilidade de transformação não apenas da cidade, mas da sociedade e figurando como forma de luta pelo direito à cidade.

Assim, a street art desempenha o papel de resistência contra as estratégias estabelecidas, contra o poder dominante da ordem distante e contesta as relações sociais, através da apropriação do espaço público e também do privado, permitindo e proporcionando a reflexão sobre as estruturas da sociedade e militando contra elas.

\section{Referências}

ANTI. Entrevista a L. H. Oliveira. Curitiba, 13 de março de 2016.

CANCLINI, Nestor García. Culturas Híbridas: Estratégias para entrar e sair da modernidade. São Paulo: Edusp, 2011.

GUSTAS. Entrevista a L. H. Oliveira. Curitiba, março de 2016.

HARVEY, David. The urban process under capitalism: a framework for analysis In: International Journal of Urban and Regional Research, v.2, n. 1-4, p. 101-131, 1978.

. A liberdade da cidade. In: MARICATO, Ermínia. et AL (org) Cidades Rebeldes: Passe livre e as manifestações que tomaram as ruas do Brasil. São Paulo: Boitempo : Carta Maior, 2013

LEFEBVRE, Henri. O direito à cidade. São Paulo: Centauro, 2001.

MARINS, L. G. Multa aumenta, mas pichação continua. Gazeta do Povo, Curitiba, 9 set. 2014. Acessado em 05 de março de 2016. Disponível em <http://www.gazetadopovo.com.br/caderno-g/multaaumenta-mas-pichacao-continua-ed8r4vsudnlhqo12l4fzwbw3y>

NASCimento, Luiz H. P. Pixação: a Arte em Cima do Muro. Cachoeira do Sul: Monstro dos Mares, 2015.

NOS tempos da São Bento. Direção: Guilherme Botelho. Brasil, 2010

OLIVEIRA; Gustavo Rebelo Coelho de. Pixação: arte e pedagogia como crime. Universidade do Estado do Rio de Janeiro, Rio de Janeiro, 2009. (Dissertação de Mestrado).

PIXO. Direção: Roberto T. Oliveira e João Wainer. Brasil, 2009.

PROSSER, Elisabeth S. Arte, representações e conflitos no meio ambiente urbano: o graffiti em Curitiba (2004-2009). Tese (Doutorado em Meio Ambiente e Desenvolvimento). Universidade Federal do Paraná. Curitiba, 2009.

Graffiti Curitiba. Curitiba: Kairós, 2010.

RAMOS, Celia Maria Antonacci. Grafite, pichação \& Cia. São Paulo: Annablume, 1994. . Grafite \& pichação: por uma nova epistemologia da cidade e da arte, 2007.

SILVA-E-SILVA, William da. Ler através das imagens: o graffiti carioca e a contracultura. Universidade do Estado do Rio de Janeiro, Instituto de Psicologia, 2008 (Dissertação de mestrado).

SOJA, Edward. Thirdspace: Journeys to Los Angeles and Other Real-and-Imagined Places. Oxford: 
Blackwell Publishing, 1996.

SPOSITO, Maria E. B. A produção do espaço urbano: escalas, diferenças e desigualdades socioespaciais. In: CARLOS, Ana F. A. et al (org) A produção do espaço urbano: agentes e processos, escalas e desafios. São Paulo: Contexto, p. 123-145, 2011.

VIANA, Maria Luiza Dias. Grafite da rua às galerias: deslocamentos imprevistos. In: Da rua: que pintura é essa?.Rio de Janeiro: FUNARTE, 2009. 